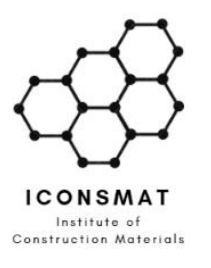

Content list available at ICONSMAT

Journal of Construction Materials

Journal homepage: www.iconsmat.com.au/publication
Article history:

Received 3 April 2021

Received in revised form

5 April 2021

Accepted 5 April 2021

Available online

7 April 2021

\title{
Utilization of rice husk ash with clay to produce lightweight coarse aggregates for concrete
}

\author{
Shegufta Zahan*1, Muhammad A. Zahin ${ }^{1}$, Muhammad M. Hossain², Raquib Ahsan² \\ ${ }^{1}$ BUET-Japan Institute of Disaster Prevention and Urban Safety, Dhaka-1000, Bangladesh \\ ${ }^{2}$ Bangladesh University of Engineering and Technology, Dhaka, Bangladesh \\ *Corresponding Author: E; shegufta174@gmail.com
}

\begin{abstract}
Rice Husk Ash (RHA) is one of the agricultural waste byproducts available widely in the world and contains a large amount of silica. In Bangladesh, stones cannot be used as coarse aggregate in infrastructure works as they are not available and need to be imported from abroad. As a result, bricks are mostly used as coarse aggregates in concrete as they are cheaper and easily produced here. Clay is the raw material for producing brick. Due to rapid urban growth and the industrial revolution, demand for brick is increasing, which led to a decrease in the topsoil. This study aims to produce lightweight block aggregates with sufficient strength utilizing RHA at low cost and use them as an ingredient of concrete. RHA, because of its pozzolanic behavior, can be utilized to produce better quality block aggregates at lower cost, replacing clay content in the bricks. The whole study can be divided into three parts. In the first part, characterization tests on RHA and clay were performed to determine their properties. Six different types of RHA from different mills were characterized by XRD and SEM analysis. Their fineness was determined by conducting a fineness test. The result of XRD confirmed the amorphous state of RHA. The characterization test for clay identifies the sample as "silty clay" with a specific gravity of 2.59 and $14 \%$ optimum moisture content. In the second part, blocks were produced with six different types of RHA with different combinations by volume with clay. Then mixtures were manually compacted in molds before subjecting them to oven drying at $120^{\circ} \mathrm{C}$ for 7 days. After that, dried blocks were placed in a furnace at $1200^{\circ} \mathrm{C}$ to produce ultimate blocks. Loss on ignition test, apparent density test, crushing strength test, efflorescence test, and absorption test were conducted on the blocks to compare their performance with the bricks. For $40 \%$ of RHA, the crushing strength result was found $60 \mathrm{MPa}$, where crushing strength for brick was observed $48.1 \mathrm{MPa}$. In the third part, the crushed blocks were used as coarse aggregate in concrete cylinders and compared them with brick concrete cylinders. Specimens were cured for 7 days and 28 days. The highest compressive strength of block cylinders for 7 days curing was calculated as $26.1 \mathrm{MPa}$, whereas, for 28 days curing, it was found $34 \mathrm{MPa}$. On the other hand, for brick cylinders, the value of compressing strength of 7 days and 28 days curing was observed as $20 \mathrm{MPa}$ and 30 $\mathrm{MPa}$, respectively. These research findings can help with the increasing demand for topsoil of the earth, and also turn a waste product into a valuable one.
\end{abstract}

DOI: 10.36756/JCM.v2.3.9 C2021 Institute of Construction Materials

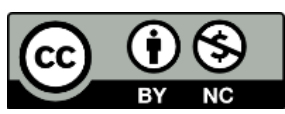

\section{Keywords}

Characterization, furnace, pozzolanic behavior, rice husk ash. 


\section{Introduction}

In Bangladesh, brick production is one of the main contributions to soil loss. Soil degradation has been identified as the most important threat to food security. The rice milling industry generates a lot of rice husk during the milling of paddy, which comes from the fields. This rice husk is mostly used as a fuel in the boilers for the processing of paddy [1]. RHA is a carbon-neutral green product and a good superpozzolan [2]. This super-pozzolan can be used in a big way to make brick aggregates. Pozzolan increases the mechanical strength of the aggregates. That is why, in this study, the authors tried to mix RHA with pure clay to see the difference. RHA usually contains around $85 \%-97 \%$ amorphous silica with a small amount of alkalis and other trace elements [3], [4]. This silica is highly porous and lightweight, with an exceedingly external surface area. Properties of RHA vary considerably according to their burning techniques [5], [6]. Depending on the time and temperature of the combustion, the silica in the ash undergoes structural transformation [7].

Rice husk is the outer cover of paddy that covers $20-25 \%$ of its weight [8]. It is removed during rice milling and is used mainly as fuel for heating in homes and rice milling industries in Bangladesh. Its heating value of 13-15 MJ/kg [9] is lower than most woody biomass fuels. However, it is extensively used in rural Bangladesh because of its widespread availability and relatively low cost. In the major riceproducing countries, much of the husk produced from the processing of rice is either burnt or dumped as waste [10]. The RHA is usually produced through a controlled and uncontrolled combustion process. The uncontrolled combustion process is used in most of the places in Bangladesh. The characteristic of RHA depends on the combustion process and variation of temperature. The fine particulate matter which is carried away from the combustion zone by the flue gas produces fly ash. The ash produced with stoker and suspension fired boilers is close to $100 \%$ amorphous. The proportion of bottom ash to fly ash depends upon the boiler type and operating conditions. Companies and researchers are encouraged to develop and improve technologies intended to reduce or minimize industrial wastes. Consequently, much effort has been expended in different areas, including agricultural production. In recent years, studies have been carried out by different researchers using wastes generated from agricultural and industrial activities as concrete-making materials. Wastes such as rice husk, sawdust, cork granules, and coconut pitch have been used as filler or aggregate for concrete. Other relevant studies that had been done recently which can shed light on future direction of young researchers focus on applications of artificial intelligence in testing concrete specimens [11], adoption of blockchain technology in the construction industry [12-16], and environmental implications of building materials in smart cities [17-28].

\section{Methodology}

Processing of raw materials included selecting the suitable types of raw materials to be used for the preparation of the specimens, primary processing of these materials to make them suitable for the next operation and determining their chemical compositions. The raw materials used in this experiment were: normal clay, RHA, and water. The complete process was divided into three parts.

1. Characterization of RHA and clay to understand their inherent properties.

2. Preparation of blocks with different proportions of RHA and clay.

3. Using crushed block aggregates as coarse material in concrete.

\section{A. Material Preparation}

In this experiment, the normal clay was used, collected from Azimpur, Dhaka, where excavation work was going on for the building construction. The lumps of the clay were crushed in order to make fine particles, and then they were normally dried in an oven for seven days to remove the inherent moisture. The clay particles were passed through no. 40 sieve to avoid any unwanted foreign particles like stones, 
large aggregates, or other substances and get homogeneous fine clay. On the other hand, RHA was collected from six different mills and then blended for 5 minutes in a blender; then passed through No.100 sieve.

Moisture absorption test, Fineness Test, XRD, and SEM test were done to characterize the rice husks from different mills. Field identification, Specific gravity test, Atterberg limit test, Optimum moisture content test, Unconfined Compression test were done to characterize the clay.

\section{B. Specimen Preparation}

Clay and ash were taken by volume percentage shown in Table 1 of total brick volume.

Table 1 - Different proportions of RHA and Clay

\section{Clay content (volume \%)}

RHA (volume \%)

\begin{tabular}{ll}
80 & 20 \\
70 & 30 \\
60 & 40 \\
50 & 50 \\
40 & 60 \\
\hline
\end{tabular}

For the mixing process, clay and RHA were taken in a bowl. For 20\% RHA of total volume with the crushed clay, proper hand mixing was done. For different percentages of RHA, the same procedure was repeated. Water was added to provide sufficient bonding so that they can hold together during molding. A total of 93 cube specimens were prepared using a mold size of $2^{\prime \prime} \times 2^{\prime \prime} \times 2$ ". Thus, 90 cube specimens were prepared for different volume fractions of RHA and the other three specimens were made of pure clay. Next, the specimens were dried in an oven for 7 days to remove excess moisture, and then they were kept in a furnace at $1200{ }^{\circ} \mathrm{C}$ for 6 hours to produce the blocks.

To compare the strength between the RHA mixed blocks and pure clay blocks, several tests were conducted. They were the crushing strength test, loss on ignition test, apparent density test, water absorption test, and efflorescence test.

\section{Preparation of Coarse Aggregates}

After the crushing test of the blocks, they were recycled to produce coarse aggregate by hammering and maintained a certain gradation. The maximum size of the coarse aggregate was one inch, and FM was 8.03. Fig. 1 shows respectively, a) how molded specimens look after they had been crushed and b) how they look after they have been hammered. 

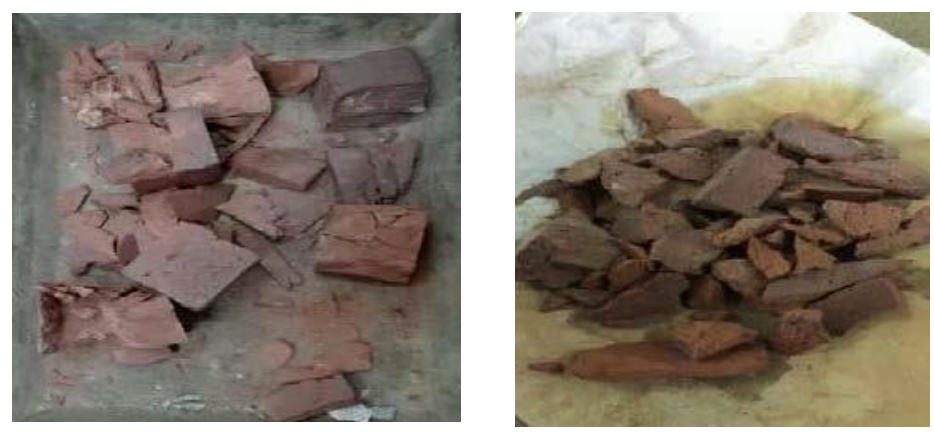

Figure 1 - Preparation of coarse aggregates

\section{Preparation of Concrete Mold}

The graded aggregates (both fine and coarse aggregates) were soaked in water for 24 hours and then air-dried in saturated surface dry (SSD) condition before mixing. For each mixture, appropriate proportions of cement: fine aggregate: coarse aggregate, 1:1.5:3 were used. Using the mixture machine, mixing was done for about two minutes. The test specimens were cast in steel cylindrical mold size of 4"x 8", and compaction was done using a vibrator nozzle. They were demolded after 24 hours. Two sets ( 3 molds in each set) of molds were made. The first set was made without mixing any admixture, but the second set was made using admixture. For the first set, the water-cement ratio was $40 \%$, and the slump value was 1.51 "whereas for the second set, the values were $45 \%$ and $1.82^{\prime}$ respectively. For the first set of molds, curing was done for 28 days, and for the second set, it was done for 7 days.

\section{Results and discussion}

\section{A. Characterization of RHA}

To determine the properties of six different kinds of RHA collected from different locations of Bangladesh, several tests were performed that include absorption capacity test, Blaine's fineness test, XRD (X-Ray Diffraction) \& SEM (Scanning Electron Microscope) analysis. Results of the performed tests are given below.

The result of the moisture absorption test of six types of RHA is shown in Fig. 2, where it can be seen that RHA 4, which is a mixture of RHA and nutshell absorbs more moisture from the atmosphere than all other RHA types.

The result of the fineness test is given in Table 2, where RHA 3 shows better fineness than the others. It was observed that RHA 3 of all the samples, were uniformly burnt in the rice mill. The more the fineness of the RHA, the more contact area of the particles will contribute to the strength of the blocks. 


\section{Moisture absorption of different mills}

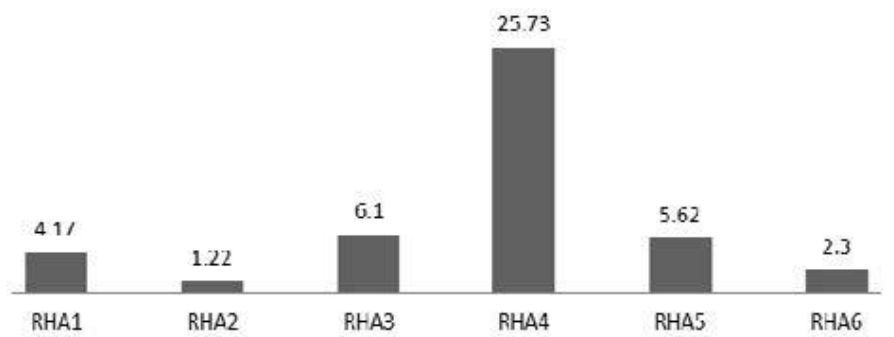

Figure 2 - Moisture absorption capacity RHA collected from different mills of Bangladesh.

From the XRD and SEM tests shown in Figs. 3 and 4, it was observed that the RHA were in amorphous states. In the case of all samples of RHA, no sharp peak was observed in XRD analysis indicating that the ash was in non-crystalline form. A rather broad peak spanning $2 \theta$ angle range of $18-30^{\circ}$, which is the characteristic of amorphous structures, was observed. On the other hand, the particle size and texture of RHA were analyzed with SEM. It was clear from 300- and 3000-times magnification that the shape of the ash particle was angular in texture.

Table 2 - Fineness of RHA from different mills

\begin{tabular}{c|c}
\hline Types of RHA & Blaine's Fineness $\left(\mathrm{cm}^{2} / \mathbf{g}\right)$ \\
\hline RHA 1 & 1150 \\
RHA 2 & 1685 \\
RHA 3 & 2720 \\
RHA 4 & 1755 \\
RHA 5 & 1673 \\
RHA 6 & 1937 \\
\hline
\end{tabular}

\section{B. Characterization of Clay}

From the field identification test, it was observed that the clay sample type was 'silty clay'. And specific gravity was 2.59; also the maximum relative density was $2 \mathrm{gm} / \mathrm{cm} 3$ at $14 \%$ moisture content. At $15 \%$ strain, the compressive strength of the soil sample was $28 \mathrm{MPa}$.

\section{Comparison of Blocks Incorporating Different Proportions of RHA with Pure Clay Blocks}

1. Loss on Ignition Test

The result of the loss on ignition test is given in Fig. 5, where the straight line represents the loss on ignition of $100 \%$ clay blocks. It was observed that at $40 \%$ RHA, minimum loss was observed for most of the RHA types except RHA 4.

2. Apparent Density Test

The apparent density for different percentages of RHA is given below for RHA 3 as it is the finest in Fig. 6, which again indicates the lowest density at $40 \%$ of RHA. 


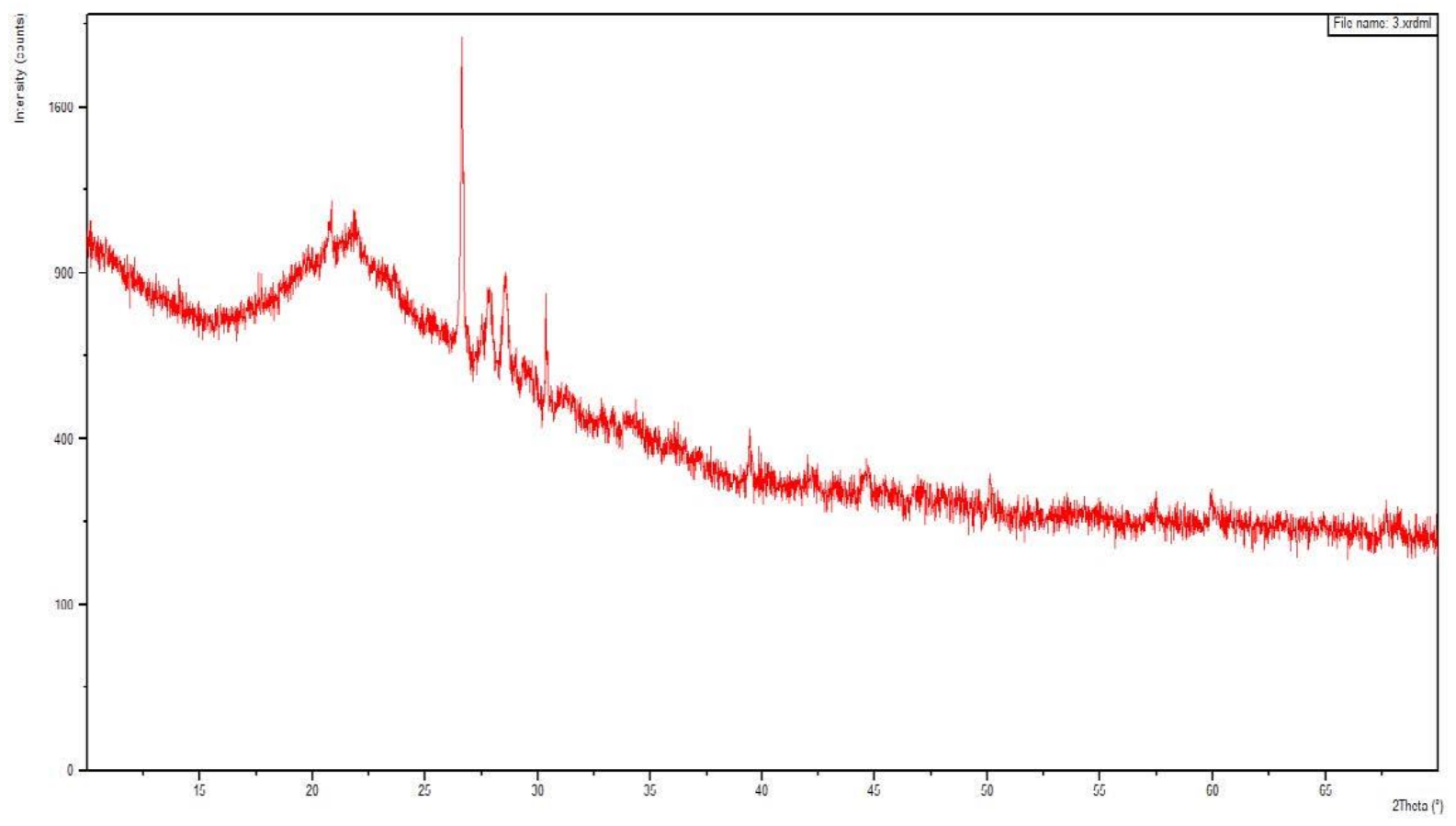

Figure 3 - XRD result of RHA 3

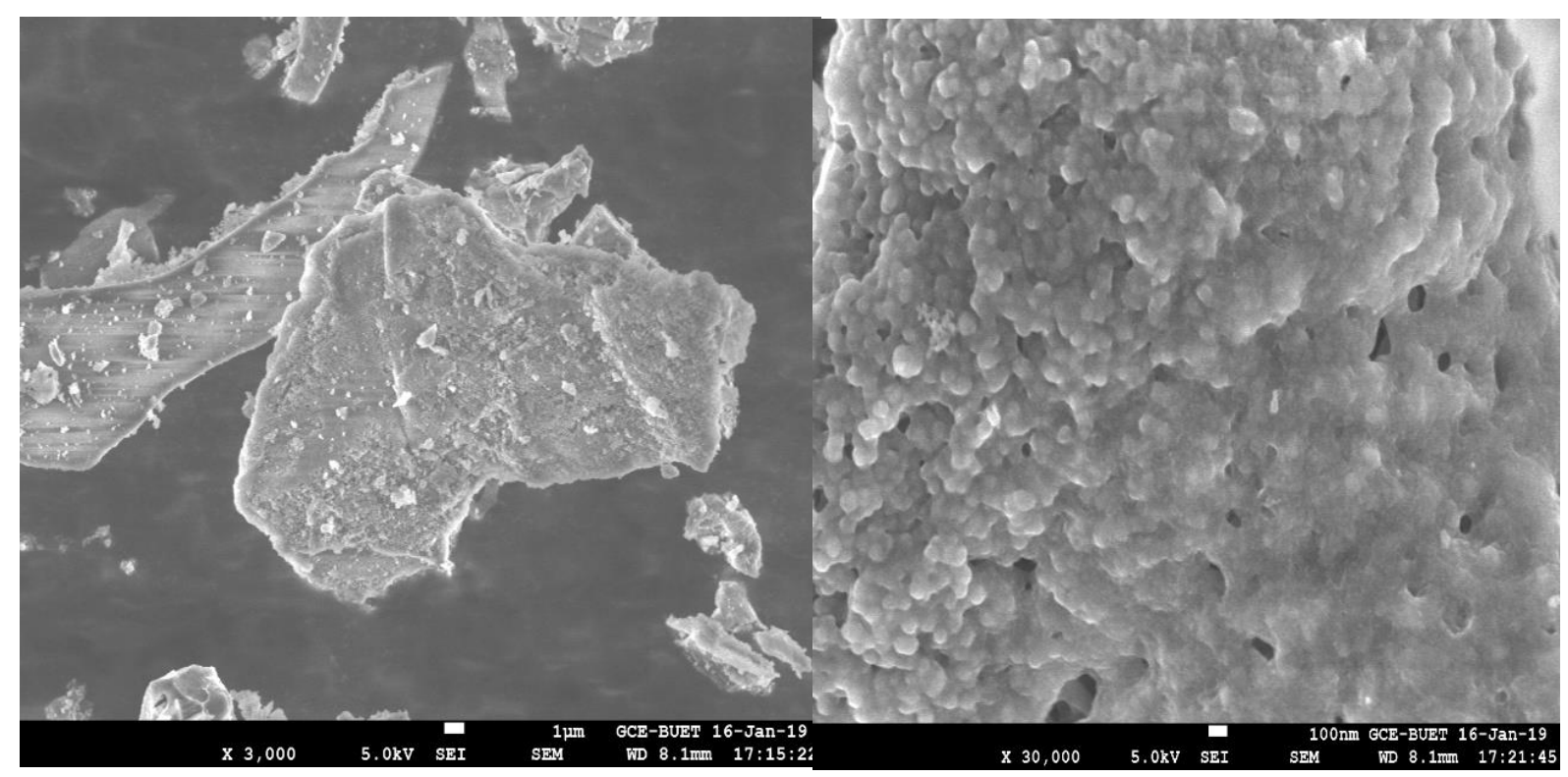

Figure 4 - SEM image of RHA 3 


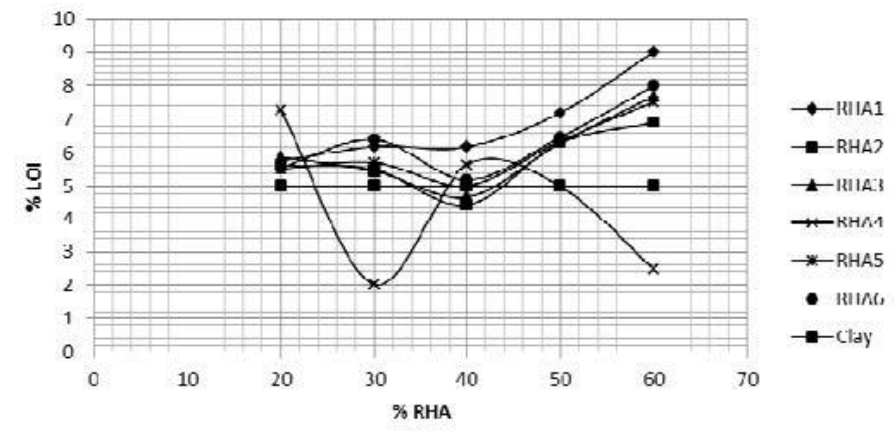

Figure 5 - Loss on ignition for different percentage of RHA for RHA from different mills

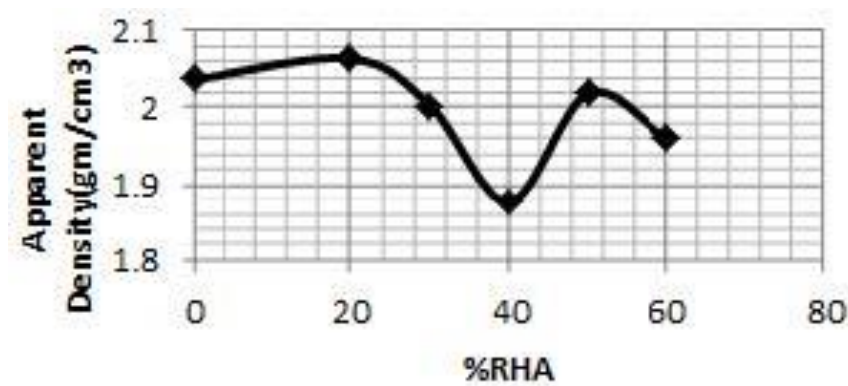

Figure 6 - Apparent density of RHA3 for different percentage of RHA.

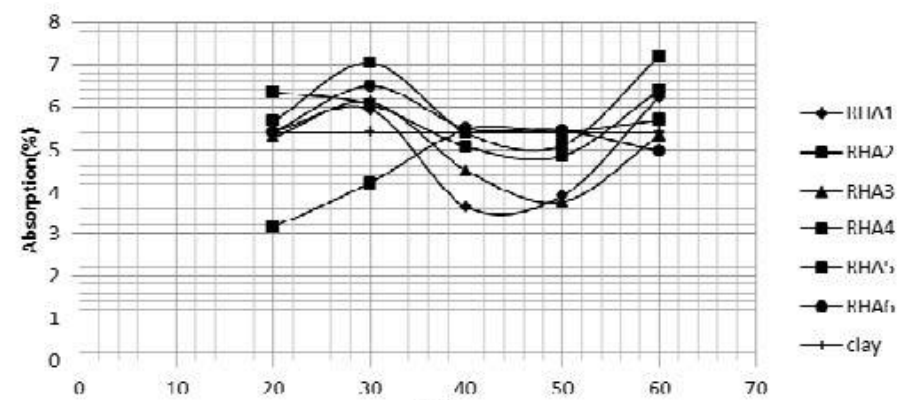

Figure 7 - Absorption of blocks incorporating different percentage of RHA from different mills.

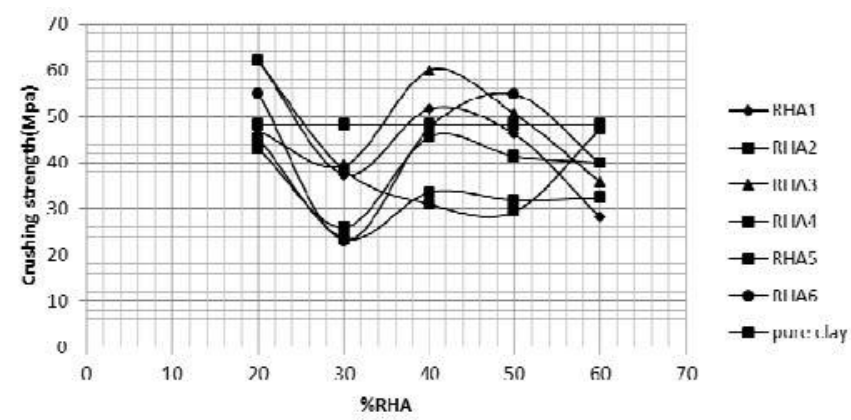

Figure 8 - Crushing strength of blocks incorporating different percentages of RHA from different mills.

3. Absorption Test

The result of the absorption test is given in Fig. 7. This figure denotes that absorption is less for 40-50\% for most of the RHA. It was also seen from Fig. 6 that the density is less for $40 \%$. It means that at 40\% RHA, the blocks not only become light weighted but also become more compacted.

4. Crushing Strength Test

The result of the crushing strength test is given in Fig. 8. This figure also indicates that for $40 \%$ of RHA, the compressive strength of the blocks incorporating finer RHA is higher than the blocks containing $100 \%$ clay.

\section{Concrete Strength Test}

Five concrete cylinder specimens $\left(4^{\prime \prime} \times 8\right)$ were prepared. The first two specimens were cured for 28 days and the last three were cured for 7 days. The result of compressive strength and tensile strength tests of these specimens will be discussed below.

1. Compressive Strength Test for 28 Days Curing 
For concrete, used materials are coarse aggregate, fine aggregate, Portland cement, and water. By hammering the crushed cubic blocks $\left(Z^{\prime \prime} \times Z^{\prime \prime} \times Z^{\prime}\right)$, coarse aggregates were prepared. The cubic blocks were made using clay and RHA maintaining the specific percentage of RHA.

a) The maximum coarse aggregate size was 1.5", and the nominal maximum size was 1 .

b) The fineness modulus (FM) was 8.03 .

c) Bulk specific gravity (oven-dry) is 1.385 .

d) Bulk specific gravity (SSD) is 1.475 .

e) Apparent specific gravity (oven dry) is 1.523 .

f) Absorption capacity is $6.5 \%$.

g) Water-cement ratio is 0.4 .

h) Slump value 1.51 inch.

After 28 days of curing, a compressive strength test was performed, and the average compressive strength of these cylinders was found $34 \mathrm{MPa}$ (4.93 ksi). On the other hand, using brick chips as coarse aggregates, compressive strength was determined $30 \mathrm{MPa}$ (4.35 ksi).

As RHA is a pozzolanic material, and it has cementitious property, it increased the compressive strength of concrete. A shear failure pattern was observed. Fig. 9 shows the shear failure pattern of the specimen.

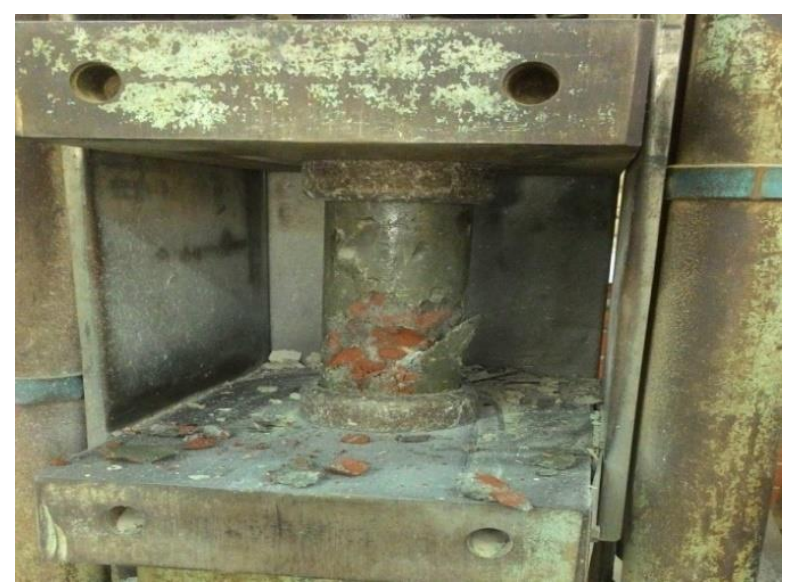

Figure 9 - Failure pattern during compressive strength test ( 28 days)

\section{Compressive Strength Test for 7 Days Curing}

For concrete, used materials were coarse aggregate, fine aggregate, Portland cement, admixture, and water.

a) Water-cement ratio 0.45 .

b) Slump value 1.82".

After 7 days of curing, a compressive strength test was done, and the average compressive strength of these cylinders was found $26.05 \mathrm{MPa}$ (3.78 ksi). When brick chips were used as coarse aggregate without mixing of admixture, the compressive strength was calculated $20 \mathrm{MPa}(2.9 \mathrm{ksi})$. As both admixture and RHA were used, the compressive strength was higher than conventional concrete. It was observed that the failure pattern of the first cylinder was a shear failure, and the second one is a columnar failure. Fig. 10 shows the failure pattern of the specimens.

\section{Tensile Strength Test for 7 Days of Curing}


After 7 days of curing, a tensile strength test was conducted at a rate of $1.12 \mathrm{kN} / \mathrm{s}$, and the average tensile strength of this cylinder was observed $2.25 \mathrm{MPa}(0.33 \mathrm{ksi})$. The tensile strength was $8.64 \%$ of the compressive strength, which was within the range of $8 \%$ to $15 \%$. The failure pattern is shown in Fig. 11.
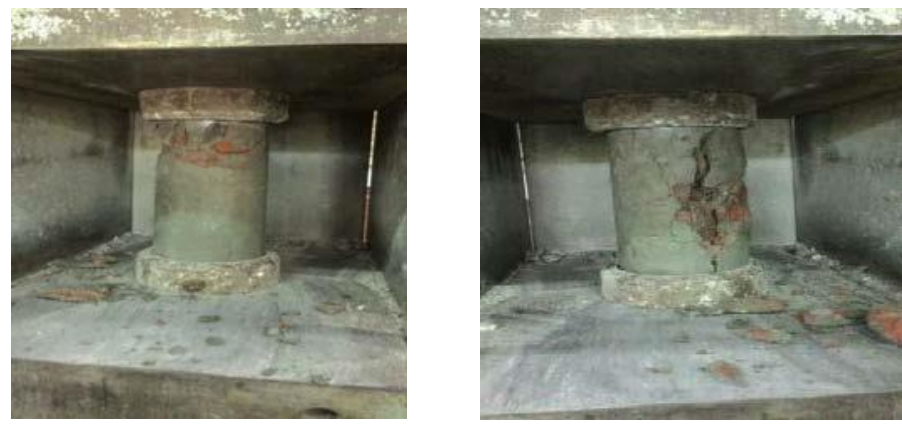

Figure 10 - Failure pattern during crushing strength test (7 days)

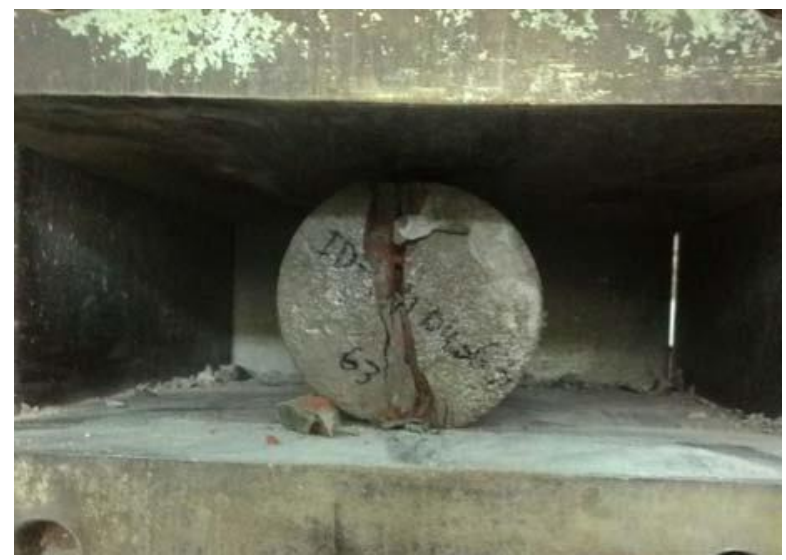

Figure 6 - Failure pattern during tensile strength test (7 days)

\section{Conclusion}

1. RHA performance increases if it is uniformly burnt from the mill and if the fineness is greater than $2500 \mathrm{~cm} 2 / \mathrm{gm}$; in this experiment RHA 3 showed these properties properly.

2. Crushing strength is first lowered with increasing percentage of RHA and then suddenly increases in 40\% RHA, then again decreases.

3. The crushing strength is higher than clay up to $40 \%$ RHA combination for the finer RHA. So $40 \%$ volume of clay brick can be replaced by RHA.

4. The absorption rate for $40 \%$ RHA is lower than other combinations, even pure clay.

5. Efflorescence effect is not excessively observable.

6. Loss on ignition is also lowest for $40 \%$ RHA except RHA 4.

7. The combination of RHA and clay only performs better than the combination of RHA, nutshell and clay.

8. Apparent density decreases at $40 \%$ that indicates light weight of the brick aggregates.

9. For RHA mixed coarse aggregate maximum absorption is observed $6.5 \%$ when normal brick aggregate absorption capacity is usually $11 \%$ to $15 \%$.

10. The strength of the RHA mixed concrete is higher than the conventional concrete. 


\section{Acknowledgment}

The authors are grateful to the Department of Civil Engineering, BUET, Department of Glass and Ceramic Engineering, BUET and the Department of Materials and Metallurgical Engineering, BUET for providing the facilities that were invaluable.

\section{References}

[1] Rice Husk Ash Market Study (2003), Confidential Report, 1.29 http://www.dti.gov.UK/renewables/Publication/pdfs/exp129.pdf

[2] Robert LD, 1990, Pozzolans for use in Low Cost housing, A state of the art report prepared for: the International Development Research Center, Ottawa, Canada.

[3] Ou E, Xi Y and Corotis R, (2007), "The Effect of Rice Husk Ash on Mechanical Properties of Concrete under High Temperatures", 18th Engineering Mechanics Division Conference (EMD2007).

[4] Basha EA, Hashim R, Mahmud HB and Muntohar AS, (2005), "Stabilization of residual soil with RHA \& cement", Constr. Build. Mater. 19: 448-453.

[5] Sugita S, 1993, "On the Economical Production of Large Quantities of Highly Reactive Rice Husk Ash", International Symposium on Innovative World of Concrete (ICI - IWC - 93), 2: 3-71, The UK Steal Association. www.uksteel.org

[6] Joseph S, Baweja D, Crookham GD and Cook DJ, 1989, "Production and utilization of rice husk ash preliminary investigations", Third CANMET/ACI International conference on fly ash, silica fume, slag and natural pozzolans in concrete, Trondheim, Norway, June 18-23: 861-878.

[7] Rashid H, Ali K, 2011, "Development of Sustainable Cement Mortar Incorporating Rice Husk Ash", KUET Institutional Repository. http://hdl.handle.net/20.500.12228/255

[8] Prasad CS, Maiti KN, Venugopal R, (2000), "Effect of RHA in white ware composition", Ceram Int 27: 629-635.

[9] Natarajan E, Nordin A and Rao AN, (1998), "Overview of combustion and gasification of rice husk in fluidized bed reactors", Biomass Bioenergy, 14: 533

[10] Chindaprasirt P and Rukzon S, (2006), "Strength, Porosity and Corrosion Resistance of Ternary Blend Portland Cement, Rice Husk Ash and Fly Ash Mortar", Constr. Build. Mater, 22: 16011606.

[11] A. Kandiri, F. Sartipi, and M. Kioumarsi, "Predicting Compressive Strength of Concrete Containing Recycled Aggregate Using Modified ANN with Different Optimization Algorithms," Applied Sciences, vol. 11, no. 2, p. 485, 2021, doi: https://doi.org/10.3390/app11020485.

[12] A. A. Hijazi, S. Perera, A. Alashwal, and R. N. Calheiros, "Blockchain adoption in construction supply chain: a review of studies across multiple sectors," in CIB World Building Congress, Hong Kong, 2019.

[13] A. A. Hijazi, S. Perera, A. M. Al-Ashwal, and R. Neves Calheiros, "Enabling a single source of truth through BIM and blockchain integration," in Proceedings of the 2019 International Conference on Innovation, Technology, Enterprise and Entrepreneurship (ICITEE 2019), 24-25 November 2019, Kingdom of Bahrain, 2019, pp. 385-393. 
[14] A. A. HIJAZI and H. A. OMAR, "Level of detail specifications, standards and file-format challenges in infrastructure projects for BIM level three," WIT Transactions on The Built Environment, vol. 169, pp. 143-154, 2017.

[15] A. A. Hijazi, "Low Zero Impact Buildings," 2017.

[16] S. Nanayakkara, M. Rodrigo, S. Perera, G. Weerasuriya, and A. A. Hijazi, "A Methodology for Selection of a Blockchain Platform to Develop an Enterprise System," Journal of Industrial Information Integration, p. 100215, 2021.

[17] F. Sartipi, "Automatic sorting of recycled aggregate using image processing and object detection," Journal of Construction Materials, vol. 1, pp. 3-3, 2020, doi: https://doi.org/10.36756/JCM.v1.2.1.

[18] F. Sartipi, "A brief critical view on the carbon-conditioning of recycled aggregate using pressure chamber," Journal of Construction Materials, vol. 2, pp. 1-4, 2020, doi: https://doi.org/10.36756/JCM.v2.1.4.

[19] F. Sartipi, "Diffusion of Innovation Theory in the Realm of Environmental Construction," Journal of Construction Materials, vol. 1, pp. 4-2, 2020, doi: https://doi.org/10.36756/JCM.v1.3.2.

[20] F. Sartipi, "Influence of $5 \mathrm{G}$ and IoT in construction and demolition waste recycling-conceptual smart city design," Journal of Construction Materials, vol. 1, pp. 4-1, 2020, doi: https://doi.org/10.36756/JCM.v1.4.1.

[21] F. Sartipi, "Preliminary structural design for extraterrestrial buildings," Journal of Construction Materials, vol. 2, pp. 2-3, 2021, doi: https://doi.org/10.36756/JCM.v2.2.3.

[22] F. Sartipi, "Publicizing construction firms by cryptocurrency," Journal of Construction Materials, vol. 2, pp. 3-1, 2021, doi: https://doi.org/10.36756/JCM.v2.3.1.

[23] F. Sartipi, "Dynamic data processing for building energy consumption," Journal of Construction Materials, vol. 2, no. 2021, pp. 2-4, 2020, doi: https://doi.org/10.36756/JCM.v2.2.4.

[24] A. Shirbazo, A. Taghavinejad, and S. Bagheri, "CO2 Capture and Storage Performance Simulation in Depleted Shale Gas Reservoirs as Sustainable Carbon Resources," Journal of Construction Materials, 2021.

[25] S. Li, L. Spry, and T. Woodall, "Corporate social responsibility and corporate reputation: A bibliometric analysis," Journal of Construction Materials, vol. 2, no. 2021, pp. 3-2, 2020.

[26] G. B. G. Ananthi, A. J. Sathick, and M. Abirami, "Experimental Investigation on Shear Behaviour of Fibre Reinforced Concrete Beams Using Steel Fibres," Journal of Construction Materials, vol. 2, pp. 1-5, 2020.

[27] N. Khelil, A. Kahil, and S. Boukais, "Mechanical contribution of silica fume and hydrated lime addition in mortars assessed by ultrasonic pulse velocity tests," Journal of Construction Materials, vol. 2, pp. 1-2, 2020.

[28] P. P. Woyciechowski, "Role of sequestration of $\mathrm{CO} 2$ due to the carbonation in total $\mathrm{CO} 2$ emission balance in concrete life," Journal of Construction Materials, vol. 2, pp. 3-4, 2021. 
